\title{
- leiomioma vaginal em cadela de 22 anos de idade - relato de caso
}

Thalita Arkan Silva Angelo

Médica Veterinária autônoma e Zootecnista

Marcus André Ferreira Sá

Professor PhD do curso de Medicina Veterinária do UBM (Barra

Mansa, RJ, Brasil)

marcus.ferreira85@hotmail.com

Simone Pontes Xavier Salles

Prof PhD em Ciências Veterinárias, Instituto de Veterinária, U-

FRRJ. Docente do curso de Medicina Veterinária do UBM.

Mariana Pimenta Fernandes

Médica Veterinária autônoma.

Júlio César Ferraz Jacob

Prof. Dr. Departamento de Reprodução e Avaliação Animal,

UFRRJ, Seropédica, Rio de Janeiro, Brasil, CEP 23890-000.

Alexandre Soares Fagundes

Prof. Msc do curso de Medicina Veterinária do UBM. 


\title{
RESUMO
}

O presente trabalho objetivou descrever um caso de leiomioma vaginal em uma cadela de 22 anos de idade. O animal em questão foi atendido na Clínica Veterinária Conforto, localizada na cidade de Quatis, no estado do Rio de Janeiro, Brasil. Tratava-se de uma fêmea que apresentava aumento de volume da região perineal e secreção vulvar mucopurulenta. Após realizar exame clínico (geral e específico do trato reprodutivo) e exames complementares, que não constataram alterações clínicas relevantes, a excisão cirúrgica foi realizada e o nódulo retirado encaminhado ao exame histopatológico, que diagnosticou leiomioma vaginal. Em 10 dias após o estabelecimento da terapêutica pósoperatória, o quadro clínico apresentou completa resolução. Atualmente, o animal se apresenta saudável. Através do presente relato fornecer informações adicionais a respeito do curso desta enfermidade em cão idoso.

Palavras-chave: Trato reprodutivo. Tumor de músculo liso. Cão. Geriatria canina.

\begin{abstract}
The present case reported objectives describe a vaginal leiomyoma in a 22-year-old bitch. The reported animal was served in the Conforto Veterinary Clinic, located in Quatis city, in Rio de Janeiro, Brazil. The perineal region was distend and mucouspurulent vulvar secretion was identified. After clinical evaluation (general and specific reproductive tract) and complementary exam performed, which did not identified relevant changes, the surgical excision was suggested and the nodule sent to histopathology exam, which diagnosed vaginal leiomyoma. After 10 days with postoperatory therapy established, the clinical condition has been completely restored. Currently, the bitch is healthy. Through this case report provide additional information about the course of this disease in old dog.
\end{abstract}

Keywords: Reproductive tract, smooth muscle tumors, dog, canine geriatric. 


\section{Introdução}

O Leiomioma representa entre $85-90 \%$ das neoplasias uterinas caninos, são os mais comuns da genitália tubular de cães e podem ser simples ou múltiplos, intraluminais ou extraluminais e, ainda não esclarecido se é de origem endócrino dependente (KARAGIANNIS et al, 2011). É uma neoplasia mesenquimal de músculo liso, frequentemente diagnosticada no trato genital, sobretudo no útero e na vagina (MACLACHLAN e KENNEDY, 2002). Esse tumor ocorre mais comumente em cadelas de meia idade ou idosas (JONES et al, 2003). Esse tipo de tumor tem sido encontrado em cães de todas as regiões do corpo em que o músculo liso esteja presente (KATAMOTO et al., 2003), porém o útero e o trato gastrintestinal são os locais mais frequentes (YILMAZ et al., 2009).

As neoplasias de origem intraluminais geralmente apresentam forma penducalada, podendo ser projetados até a região vultar; já os de origem extraluminais apresentam projeção em região de períneo e progressão lenta (KLEIN, 2001). Geralmente, as neoplasias intraluminais podem ser removidos mediante ligaduras no pedúnculo. Já os extraluminais, são pouco vascularizados e encapsulados, sendo sua remoção por divulsão. Caso não seja possível a retirada de toda massa tumoral, pode-se utilizar a radioterapia como ferramenta adicional ao tratamento (ETTINGER e FELDMAN, 2007).

Tumores vaginais e vulvares em cadelas se deve a influência hormonal que ocorre nesses órgãos por ocasião do cio (MENDONÇA et al., 2012). Os hormônios sexuais podem influenciar seu surgimento e frequentemente estão associados a cistos foliculares ou neoplasias secretores de estrógenos, hiperplasia endometrial, hiperplasia mamária e neoplasia mamária (SCHLAFER e MILLER, 2007). A relação entre leiomioma e os receptores esteroidais tem sido bem estudada em cães, mostrando que as neoplasias de músculo liso do trato genital expressam receptores hormonais de esteróide (FRANCISCO e BIRGIT, 2008). Os hormônios sexuais esteroidais apresentaram efeito em três etapas da cascata da carcinogênese: iniciação, promoção e progressão. Das 32 neoplasias de musculatura lisa estudados em cadela, 56,3\% deles apresentaram receptores para estrógeno e $84,4 \%$ deles para progesterona (MILLAN et al., 2007). A maior parte dos leiomiomas do trato genital canino expressa receptores de progesterona, respondendo ao 
tratamento utilizando antagonista de progesterona com a redução no seu tamanho (ROLLON et al., 1997).

Alguns sinais encontrados nos animais acometidos são aumento de volume em região de períneo, prolapso pela vulva de tecido neoplásico, disúria, polaciúria, tenemos, descarga vulvar (KLEIN, 2001). Pode haver ainda hemorragia vaginal intensa, desconforto e, mais raramente, retenção urinária (FERREIRA e PINTO, 2008). Podem ocorrer constipação e/ou até mesmo estar associado a quadros mais severos de enfermidades como distocia obstrutiva, hérnia inguinal, dentre outras (SINGH et al., 2014; PRASHANTH et al., 2015).

O diagnóstico clínico pode ser alcançado através do exame físico do paciente, exame de ultrassonografia e confirmado através da análise histológica (FERREIRA e PINTO, 2008). O diagnóstico diferencial é feito para prolapso vaginal, neoplasia uretral, prolapso uterino, hipertrofia do clitóris, pólipo, abscesso ou hematoma vaginal (TILLEY e SMITH JR, 2003).

Eficiente recurso para o tratamento do leiomioma é a ressecção cirúrgica da massa neoplásica por meio da episiotomia, concomitante com a ovariosalpingohisterectomia (OSH) (MENEGASSI et al., 2016). Quando o tratamento cirúrgico não pode ser empregado devido ao desenvolvimento tumoral e aos fatores de risco inerentes ao animal, foi estabelecido com sucesso protocolo homeopático (FERREIRA e PINTO, 2008). Aglepristone, antagonista competitivo da progesterona, já foi utilizado como recurso terapêutico em uma cadela de 12 anos de idade, não ovariohisterectomizada, que apresentava fibroma vaginal e foi observado redução no diâmetro tumoral (ROLLON et al., 1997).

O prognóstico para as neoplasias benignas assintomáticas não tratadas é bom, o contrário pode ser afirmado nos casos em que a massa tumoral aumente de tamanho e faça compressão do trato gastrointestinal ou urinário. O prognóstico após a OSH é excelente em casos de neoplasias benignos e bom nas neoplasias malignas, caso não haja evidência de metástase ou infiltração local (FOSSUM, 2001). Entretanto, o fator idade pode culminar em um quadro inesperado ou até na pronta recuperação do estado de higidez do animal.

Estudos que envolvam neoplasias vaginais são escassos na medicina veterinária, principalmente os relacionados a animais idosos, onde os fatores de risco inerentes a 
idade podem agravar o quadro do animal. Sendo assim, o presente trabalho teve como objetivo descrever um caso de leiomioma vaginal em uma cadela de 22 anos de idade.

\section{Relato de Caso}

Uma cadela de 22 anos de idade foi atendida na Clínica Veterinária Conforto, situada no município de Quatis, região norte fluminense do estado Rio de Janeiro. Os principais relatos do proprietário foram o aumento de volume da região perineal e o prolongamento do período estral, além de secreção muco-purulenta vaginal.

Durante o exame clínico do animal, o toque do canal vaginal revelou a presença de nodulação. Desta forma, suspeitou-se de formação neoplásica e optou-se pelo tratamento cirúrgico (excisão).

Como exames pré-operatórios, foram solicitados hemograma com pesquisa para hematozoário, bioquímica sérica (uréia, creatinina, alanina aminotransferase - ALT- e aspartato aminotransferase - AST). O hemograma revelou anemia normocítica normocrômica; já as bioquímicas séricas não revelaram alteração da saúde da cadela (quadro 1), bem como a ultrassonografia transabdominal. Após o resultado do exame ultrassonográfico, aliado à avaliação do paciente que se apresentou clinicamente bem, optou-se pelo tratamento cirúrgico imediato, mesmo diante do quadro de anemia normocítica normocrômica. O proprietário da cadela foi conscientizado dos riscos inerentes ao ato cirúrgico, concordando com o tratamento proposto através de preenchimento e assinatura de termo de responsabilidade para realização da intervenção cirúrgica imediata. 
Quadro 1. Valores hematológicos encontrados nos exames de hemograma e bioquímica sérica.

\begin{tabular}{|c|c|c|c|c|c|}
\hline \multicolumn{3}{|c|}{ Eritrograma } & \multicolumn{3}{|c|}{ Leucograma } \\
\hline Célula & Resultado & Referência & Célula & Resultado & Referência \\
\hline Hemácias & 4.07 & $\begin{array}{l}5.200 \text { a } 7.500 \\
\text { milhões } / \mathrm{mm}^{3}\end{array}$ & Leucócitos & 12.800 & $\begin{array}{c}6.000 \mathrm{a} \\
17.000 / \mathrm{mm}^{3}\end{array}$ \\
\hline Hemoglobina & 9.2 & 12.0 a $18.0 \mathrm{~g} / \mathrm{dl}$ & Basófilo & 0 a $1 \%$ & 0 \\
\hline Hematócrito & 26.9 & 37 a $53 \%$ & Eosinófilo & 0 & 2 a $10 \%$ \\
\hline VGM & 66.0 & 60 a $72 \%$ & Mielocitos & 0 & 0 \\
\hline CHGM & 34,3 & 34 a $38 \%$ & Segmentados & 58 & 60 a $75 \%$ \\
\hline & & & Linfocitos & 36 & 12 A $30 \%$ \\
\hline & & & Monocitos & 3 & 3 A $9 \%$ \\
\hline \multicolumn{6}{|c|}{ Complemento } \\
\hline & \multicolumn{2}{|c|}{ Resultados } & \multicolumn{3}{|c|}{ Valores normais } \\
\hline Plaquetas & \multicolumn{2}{|c|}{334.000} & \multicolumn{3}{|c|}{200.000 a $500.000 / \mathrm{mm}^{3}$} \\
\hline \multicolumn{6}{|c|}{ Bioquímica sérica } \\
\hline & \multicolumn{2}{|c|}{ Resultados } & \multicolumn{3}{|c|}{ Valores normais } \\
\hline Uréia & \multicolumn{2}{|r|}{27} & \multicolumn{3}{|c|}{$15-40 \mathrm{mg} / \mathrm{dl}$} \\
\hline Creatinina & \multicolumn{2}{|r|}{0,6} & \multicolumn{3}{|c|}{$0,5-2,0 \mathrm{mg} / \mathrm{dl}$} \\
\hline ALT & \multicolumn{2}{|r|}{52} & \multicolumn{3}{|c|}{$21-102 \mathrm{Ul} / \mathrm{l}$} \\
\hline AST & \multicolumn{2}{|r|}{24} & \multicolumn{3}{|c|}{$20-156 \mathrm{Ul} / \mathrm{l}$} \\
\hline
\end{tabular}

O exame ultrassonográfico revelou não haver nenhuma alteração a nível de útero e ovários. O ovário direito com medida de $1,66 \mathrm{~cm} \mathrm{x} 1,03 \mathrm{~cm}$ e o esquerdo não foi 
visualizado. Em região vaginal observou-se uma massa medindo 5,02 cm x 2,93 cm, hiperecóica, sem apresentar cistos ou material anecóico que sugere ser constituída de material muscular. Não se observou nenhuma alteração nos órgãos da cavidade abdominal.

Para realização da ressecção cirúrgica foi realizada a medicação pré-anestésica utilizando Cloridrato de Acepromazina $(0,1 \mathrm{mg} / \mathrm{kg}$, por via intramuscular) associado Cloridrato de Tramadol (2 mg/kg, por via intramuscular). Após 15 minutos, para realizar a indução do animal ao plano anestésico, utilizou-se Propofol (4mg/kg, por via endovenosa) e a manutenção do plano anestésico foi realizada utilizando anestésico geral Isoflurano, por via inalatória.

Procedeu-se então a técnica de Episiotomia para acessar a massa tumoral com o animal em decúbito ventral. $\mathrm{O}$ animal teve o ânus ocluído por sutura de Bolsa de Tabaco com fio Nylon 2-0 (agulha traumática e curva), para evitar contaminação do campo cirúrgico por fezes. Para identificação e preservação do meato urinário, promoveu-se a colocação de sonda uretral. A incisão cutânea foi realizada na linha média através da comissura dorsal dos lábios vulvares até a região distal do músculo esfinctérico anal externo. A incisão cirúrgica continuou até a parede vaginal, possibilitando a exposição de $2 / 3$ da massa tumoral.

Após obtido acesso à massa tumoral, seccionou-se o tecido peritumoral até completa soltura da mucosa vaginal. Após a remoção completa da massa tumoral, a incisão foi fechada em três camadas. Primeiramente a mucosa vaginal, com sutura contínua, posteriormente reaproximou-se a musculatura e o tecido subcutâneo em padrão contínuo. Ao final do procedimento cirúrgico, removeu-se a sonda uretral e a sutura anal de Bolsa de Tabaco (figura 1).

A massa tumoral retirada no procedimento cirúrgico foi encaminhada para exame histopatológico, que evidenciou fibras musculares lisas maduras, arranjadas em feixes multidirecionais, compostas por agregados de células fusiformes, apresentando núcleo com morfologia "charutóide" e citoplasma escasso eosinofílico (figura 2).

\section{Discussão}

O relato do proprietário a respeito do fato da cadela apresentar grandes períodos de cio e curtos intervalos entre eles pode representar um desequilíbrio hormonal com 
elevadas concentrações séricas de estrógeno. Esse desequilíbrio pode ter sido um dos fatores predisponente para o desenvolvimento do leiomioma vaginal, que expressam receptores hormonais de esteróide (FRANCISCO e BIRGIT, 2008).

Optou-se pelo tratamento cirúrgico para reversão do quadro, com exérese do tecido tumoral, imediatamente após a consulta clínica, evitando assim que atingisse diâmetro ainda maior. Neoplasias vaginais podem atingir grandes dimensões, o que poderia dificultar a completa remoção cirúrgica caso fosse realizada posteriormente, propiciando o aparecimento de recidivas (JOHNSTON et al., 2001; TRALL, 2007).

A técnica cirúrgica preconizada pela maioria dos autores para esse caso é a excisão cirúrgica associada a OSH (FOSSUM, 2001; MENDONÇA et al., 2012; MENEGASSI et al., 2016). Entretanto, não foi realizada a OSH devido ao tempo necessário (prolongado) para realização deste procedimento cirúrgico. Sendo assim, no presente relato, optou-se por realizar apenas a exérese da massa neoplásica. A ovariosalpingohisterectomia foi realizada 60 dias após, período em que não foi observada recidiva. Neoplasias vaginais malignos podem causar recidiva em curto período de tempo, como observado em estudo recente (MENEGASSI et al., 2016), em que ocorreram duas recidivas de leiomiossarcoma em período inferior a 60 dias.

A confirmação de leiomioma vaginal foi realizada através do exame histopatológico realizado. A caracterização histológica foi semelhante o estudo anterior (HENDLUND, 2005), que descreveram células com citoplasma eosinofílico de limites indistintos, núcleo alongado a ovoide, como descrito anteriormente.

$\mathrm{O}$ quadro apresentado pela cadela coincide com os relatos da literatura, na qual neoplasias vaginais e vulvares acometem normalmente cadelas idosas e não castradas, de origem hormônio dependentes (MACLACHLAN e KENNEDY, 2002; JONES et al, 2003; ETTINGER e FELDMAN, 2007; KARAGIANNIS et al, 2011). A presença de corrimento vaginal purulento e aumento da região perineal também foi relatada por outros autores como parte dos sinais clínicos de casos de neoplasias vaginais (KLEIN, 2001; ETTINGER e FELDMAN, 2007; SOUZA et al., 2008).

Diante do caso clínico apresentado, pode-se afirmar que a conduta tomada pela equipe veterinária no atendimento à cadela foi adequada. A saúde do animal foi prontamente reestabelecida e a mesma se encontra clinicamente saudável até os dias atuais. 


\section{Considerações Finais}

Espera-se a partir do presente relato fornecer informações adicionais a respeito do curso desta enfermidade em cão idoso. Foi possível observar que apesar de o paciente apresentar 22 anos, idade bastante avançada para esta espécie, todo o procedimento ocorreu sem imprevistos durante a cirurgia ou efeitos adversos no período de recuperação clínica. Vale ressaltar também estado geral clínico favorável apresentado inicialmente pelo paciente. Sendo assim, recomenda-se o procedimento em animais idosos que apresentem exames complementares satisfatórios.

\section{Referências}

ETTINGER, S.J.; FELDMAN, E.C. Tratado de Medicina Interna Veterinária. $1^{\text {a }}$ ed. São Paulo: Manole., v.2, p.2273-2274, 1997.

FERREIRA, M.I.C.; PINTO, L.F. Homeopathic treatment of vaginal leiomyoma in a dog: case report. Int J High Dilution Res, v. 7, p. 152-158, 2008.

FOSSUM, T.W. Cirurgia de Pequenos Animais. São Paulo: Rocca, 2001.

FRANCISCO, A.U.; BIRGIT, P. Cervical leiomyoma in an aged goat leading to massive hemorrhage and death. Can Vet J, v. 49, p. 177-179, 2008.

HENDLUND, CS. Neoplasias uterinas. In: FOSSUN, T. W. Cirurgia de pequenos animais. 2ed. São Paulo: Roca, p.637-638, 2005.

JOHNSTON, D.S.; KUSTRIZ, R.V.M.; OLSON, P.N.S. Canine and feline theriogenology. Philadelphia: Saunders, 2001.

JONES, T.C.; HUNT, R.D.; KING, N.W. Patologia veterinária. 6.ed. São Paulo: Manole, 2003.

KARAGIANNIS, G.S.; PELEKANIS, M.; LOUKOPOULOS, P.; HARIS, N.; VERVERIDIS, H.N.; KALDRYMIDOU, E. Canine Uterine Leiomyoma with Epithelial Tissue Foci, Adenomyosis and Cystic Endometrial Hyperplasia. Case Report Vet Med, v. 2011, p. 1-4, 2011. 
KATAMOTO, H.; KUMAGAI, D.; KOUZAI, N.; TAKIGAMI, S.; KUAMURA, M.; YAMATE, J.; KOTANI, T. Space-occupying leiomyoma in the pelvic canal of a dog. J Small Anim Pract, v. 44, p. 277-279, 2003.

KLEIN, M.K. Tumors of the female reproductive system. In: Wihtrow, SJ; Macewen, EG. Small animal clinical oncology. 3.ed. Philadelphia: Saunders, p.445-454, 2001.

MACLACHLAN, N.J.; KENNEDY, P.C. Tumor of the genital systems. In: Meuten DJ, editor. Tumors in domestic animals. $4^{\text {th }}$ ed. Iowa State Press, Ames, p. 547-573, 2002.

MENDONÇA, M.L.; SOUZA, R.; CARVALHO, V.G.; FREITAS, N.; PERIN, R.C.; SILVA, M. Leiomioma vaginal em cadela SRD. Revista Eletrônica Nutritime, v. 9, p. 1875-1878, 2012.

MENEGASSI, C.C.; MARTINS, I.C.S.; PEREIRA, G.M. GOMES, L.G.; BEZERRA, K.S.; SPILLER, P.R.; MARTINI, A.C.; SOUZA, R.L.; RIBEIRO, A.P. Aspectos clínicos, cirúrgicos, histológicos e pós-operatórios de oito cadelas com leiomioma vaginal. Arq Bras Med Vet Zootec, v. 68, p. 307-312, 2016.

MILLAN, Y.; GORDON, A.; DE-LOS MONTEROS, A.E.; REYMUNDO, C.; DE LAS MULAS, J.M. Steroid receptors in canine and human female genital tract tumors with smooth muscle differentiation. J Comp Pathol v. 136: p. 197-201, 2007.

PRASHANTH, C.; SUDHA, G.; JAYAKUMAR, C.; YUGANDHAR, M. Vaginal leiomyoma as a cause of obstructive dystocia in a bitch. Indian Journal of Canine Practice, v.7, p. 1-4, 2015.

ROLLON, E.; MILLAN, Y.; MARTIN DELAS, M.J. Effects of aglepristone, a progesterone receptor antagonist, in a dog with a vaginal fibroma. J Small Anim Pract, v. 49, p. 41-43, 1997.

SCHLAFER, D.H.; MILLER, R.B. Female genital system. In: Maxie MG, editor, Jubb, Kennedy, Palmer. Pathology of Domestic Animals. 5th ed. Philadelphia: Elsevier, 2007. p.429-564. 
SINGH, K.; BODH, D.; GOPINATHAN, A.; MUTHALAVI, M.A.; PALAKKARA, S. A case of concurrent inguinal hernia and vaginal leiomyoma in a bitch successfully treated surgically. Res J Vet Pract, v. 2, p. 1-4, 2014.

SOUZA, M.G.; RENNÓ, P.P.; COSTA, J.L.P. Relato de caso - leiomioma vaginal em cadela. Revista Científica Eletrônica de Medicina Veterinária, v. 10, p. 1-7, 2008.

TILLEY, L.P.; SMITH JR., F.W.K. Consulta Veterinária em 5 minutos - espécie canina e felina. $2^{\mathrm{a}}$ ed. São Paulo: Manole, 2003.

TRALL, M. A. Hematologia e Bioquímica Veterinária. 1. ed. São Paulo: Roca, 2007.

YILMAZ, R.; AKKOC, A.; OZYIGIT, M.O. Ileal leiomyoma in a captive zebra (Equus burchelli). J Vet Anim Sci, v. 33, p. 443-446, 2009. 